\title{
SURVEILLANCE ET REDÉFINITION DU PÉRIL CLÉRICAL : LES DISPOSITIFS DE SURVEILLANCE DU CULTE À L'ÉPREUVE DE LA LAÏCITÉ SOUS LA TROISIÈME RÉPUBLIQUE
}

\author{
Magali Della Sudda
}

L'Harmattan | « Cultures \& Conflits »

2019/2 n 114-115 | pages 55 à 78

ISSN 1157-996X

Article disponible en ligne à l'adresse :

https://www.cairn.info/revue-cultures-et-conflits-2019-2-page-55.htm

Distribution électronique Cairn.info pour L'Harmattan.

(C) L'Harmattan. Tous droits réservés pour tous pays.

La reproduction ou représentation de cet article, notamment par photocopie, n'est autorisée que dans les limites des conditions générales d'utilisation du site ou, le cas échéant, des conditions générales de la licence souscrite par votre établissement. Toute autre reproduction ou représentation, en tout ou partie, sous quelque forme et de quelque manière que ce soit, est interdite sauf accord préalable et écrit de l'éditeur, en dehors des cas prévus par la législation en vigueur en France. Il est précisé que son stockage dans une base de données est également interdit. 


\section{Surveillance et redéfinition du péril clérical : les dispositifs de surveillance du culte à l'épreuve de la laïcité sous la Troisième République}

Surveillance and the Redefinition of Clerical Threat: Religious Surveillance and Laicity under the Third Republic

\section{Magali Della Sudda}

\section{(2) OpenEdition}

\section{Édition électronique}

URL : http://journals.openedition.org/conflits/20942

DOI : 10.4000/conflits.20942

ISSN : $1777-5345$

Éditeur :

CCLS - Centre d'études sur les conflits lilberté et sécurité, L'Harmattan

\section{Édition imprimée}

Date de publication : 20 décembre 2019

Pagination : 55-78

ISBN : 978-2-343-19249-9

ISSN : 1157-996X

Distribution électronique Cairn

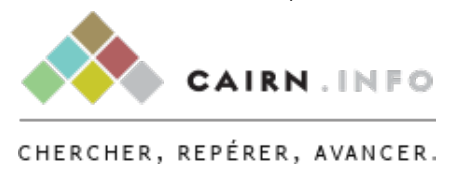

\section{Référence électronique}

Magali Della Sudda, « Surveillance et redéfinition du péril clérical : les dispositifs de surveillance du culte à l'épreuve de la laïcité sous la Troisième République », Cultures \& Conflits [En ligne], 114-115 | été/automne 2019, mis en ligne le 01 janvier 2023, consulté le 09 janvier 2020. URL : http:// journals.openedition.org/conflits/20942 ; DOI : 10.4000/conflits.20942 


\section{Surveillance et redéfinition du péril clérical : les dispositifs de surveillance du culte à l'épreuve de la laïcité sous la Troisième République}

\section{Magali DELLA SUDDA}

Magali Della Sudda est chargée de recherche au CNRS, Centre Emile Durkbeim, Sciences Po Bordeaux. Après avoir soutenu une thèse sur la politisation des femmes conservatrices avant le droit de vote en France et en Italie, elle prépare une babilitation à diriger les recherches sur les recompositions des droites autour $d u$ genre entre 2012 et 2017. Parmi ses publications : " Ripostes catholiques" ", Genre, sexualité \& société, 18, 2017 (avec Martina Avanza); "When male heterosexual leaders politicize gender and sexual issues: The logic of representation in the 2014 Bordeaux municipal election campaign ", French Politics, 14, 2016/1 (avec Clément Arambourou, Fanny Bugnon, Victor Marneur, Frédéric Neyrat et Marion Paoletti; "Gender, Fascism and Right-Wing in France between the wars: the Catholic matrix ", Politics, Religion \& Ideology (Ex Journal of Totalitarian Movements), vol.13, 2012/2.

Comment des femmes, catholiques et conservatrices, sont-elles entrées dans le viseur de la surveillance politique ? Il faut revenir sur le contexte spécifique des transformations du régime républicain entre 1902 et 1914 pour comprendre comment, de manière apparemment paradoxale, des associations catholiques de femmes conservatrices ont fait l'objet de surveillance, passant du statut de citoyennes sans le vote à celui de menace pour l'ordre républicain. Dans les années 1890 et jusqu’à la Grande guerre, les catholiques hostiles à un ordre politique libéral et pourfendeurs de l'égalité sociale sont suspects d'allégeance à une puissance étrangère, le Vatican. De grandes bourgeoises et des aristocrates, des groupes sociaux considérés comme des facteurs de stabilité pour l'ordre social et politique conservateur, passent ainsi de la catégorie de gardiennes de l'ordre social à celle de menaces pour la République. Si « tout 
Paris avait un dossier » à la Préfecture de police, selon les mots du Préfet Andrieux (1840-1931), le Tout-Paris aussi est scruté avec attention. Cette surveillance d'un genre particulier donne à voir les transformations des catégories d'action étatique et leur élargissement à des catégories sociales qui jusqu'alors étaient considérées comme stabilisatrices de l'ordre social et politique.

Le régime de laïcité instauré entre 1880 et 1915 définit un ordre social et politique libéral dans lequel l'État n'intervient pas dans les affaires religieuses. Pour autant, la surveillance religieuse n'est pas abandonnée. Elle occupe même une part significative des cartons d'archives de la préfecture de police de Paris et du Ministère de l'Intérieur et des cultes ${ }^{1}$. En août 1904, la publication dans le Figaro de documents indiquant l'existence d'un système de surveillance des officiers catholiques dans l'armée suscite un scandale. "L'affaire des fiches » provoque la chute du ministère Combes et accélère la mise sur agenda de la séparation des Églises et de l'État. Si l'on saisit la logique étatique qui préside à l'observation des officiers au régime pour s'assurer de leur loyauté, comment expliquer que des femmes pieuses, exclues des joutes politiques et peu suspectes de violence - grandes bourgeoises, braves paysannes, châtelaines de l'Ouest ou baronnes d'Empire - entrent, elles aussi, dans le viseur de l'État ? Les politiques de laïcité ont suscité une opposition féminine qui a orienté le regard de la police politique vers des individus jusqu'alors considérés comme des facteurs de stabilité politique - les libéraux et les catholiques ralliés à la République -, et des groupes sociaux habituellement peu suspects de déstabilisation sociale entrent dans la catégorie des ennemis du régime.

\section{Nouvelles suspectes}

La loi de Séparation cristallise un point d'équilibre entre la liberté de conscience et la neutralité de l'État à l'égard des cultes. Le judaïsme n'est pas perçu comme une menace pour l'ordre républicain ${ }^{2}$, tandis que le protestantisme est porteur de laïcité ${ }^{3}$. L'islam n'est pas considéré comme un problème pour la République ${ }^{4}$. En revanche, les catholiques sont soupçonnés d'hostilité au régime républicain. Les jésuites sont mis hors d'état de former les consciences des futurs citoyens par le décret du 29 mars 1880 qui les exclut de l'instruction publique; le "phénomène congréganiste » est conjuré par la loi de 1901 qui impose une autorisation par la préfecture ; le péril clérical revêt

1. Ce commissaire spécial de la Vienne fait état en 1904 de 28,5\% de rapports consacrés aux activités religieuses; Mathieu M., "Le rôle politique des commissaires spéciaux de la police des chemins de fer dans la Vienne entre 1874 et 1914 », in Vigier Ph. (dir.), Maintien de l'ordre et polices en France et en Europe au XIXe siècle, Société d'Histoire de la Révolution de 1848 et des Révolutions du XIXe siècle, Paris, Créaphis, 1987, pp. 151-166.

2. Birnbaum P. et Berlière J.-M., La France de l'affaire Dreyfus, Paris, Gallimard, 1994.

3. Cabanel P., Le Dieu de la République. Aux sources protestantes de la laïcité (1860-1900), Rennes, Presses universitaires de Rennes, 2003.

4. Luizard P.-J. (dir.), Le choc colonial et l'islam, Paris, La Découverte, 2006. 
alors le visage ordinaire des laïcs : le camelot monarchiste qui défend la tiare et la couronne, la paroissienne zélée ou la religieuse sécularisée.

La ligueuse catholique, qui entend « résoudre la question sociale les Évangiles à la main », entre ainsi dans le viseur des autorités républicaines. Ces nouvelles suspectes réactualisent le stéréotype de l'ennemie de la République forgé durant la Révolution ${ }^{5}$. Les modalités de la surveillance des groupes féminins par des agents de police, qui sont exclusivement des hommes ${ }^{6}$, amènent à interroger la manière dont le regard des hommes de la police informe sur les agissements des femmes catholiques 7 . Ce travail de mise en forme révèle les schèmes de représentation ordinaires des institutions qui président à l'activité de surveillance de ces militantes et fidèles catholiques, fort éloignées dans leur sociologie et leur mode d'action, des anarchistes et socialistes qui sont dans le collimateur de la police politique ${ }^{8}$.

\section{Les archives de la République}

À la Préfecture de police de Paris, les dossiers relatifs aux organisations politiques catholiques et nationalistes, ceux consacrés aux manifestations du 27 juillet 1902 contre la fermeture des écoles congréganistes, et les fiches individuelles de militants et personnalités catholiques ont constitué la base de cette recherche. Les militantes ont fait l'objet de fiches de renseignement, comme l'indiquent les numéros de renvoi à ces fiches dans les rapports de police. Le déménagement des archives à Pantin a achevé la destruction de toutes les fiches de militantes de la Ligue patriotique des Françaises et des comités de dames, probablement en raison du faible intérêt porté par les services concernés. II n'a donc pas été possible de les consulter. En revanche, les Archives nationales ont versé des dossiers de militantes avec des descriptions succinctes.

Les archives de l'administration centrale ont été consultées : la série F19 « administration du Culte » où est déposée une partie des fonds de la direction des Cultes, devenu Bureau central des cultes du Ministère de I'Intérieur en 1911, comporte également des dossiers qui peuvent éclairer la surveillance des fidèles. Ils sont toutefois nettement moins nombreux et concernent la mise en application de la loi de 1901 et de la circulaire sur la fermeture des écoles congréganistes. L'état des fonds inventoriés témoigne à la fois du développement de la bureaucratie chargée de la surveillance et

5. Martin J.-C., La révolte brisée. Femmes dans la Révolution française (1770-1820), Paris, A. Colin, 2008.

6. Pruvost G., De la « sergote » à la femme flic. Une autre histoire de l'institution policière, 19352005, Paris, La Découverte, 2006.

7. Ces groupes ne supplantent toutefois guère dans le viseur de la police les anarchistes et socialistes - «églantinards » objets d'une surveillance resserrée depuis l'assassinat de Carnot et l'agression du président Loubet.

8. Sur les archives de police voir Berlière, J.-M., "Archives de police/historiens policés ? ", Revue d'histoire moderne et contemporaine, vol. $48, \mathrm{n}^{\circ} 4$ bis, $\mathrm{n}^{\circ} 5$, pp. 57-68. 
des orientations successives prises par celle-ci. La sous-série F7 " police » du Ministère de l'intérieur, concerne la surveillance des partis politiques et associations. Elle a fait l'objet d'un dépouillement exhaustif pour les ligues féminines catholiques (F7 13215 à F7 13 218), les congrégations 9, les ligues nationalistes 10 , les groupes monarchistes 11.

L'actualisation des dispositifs de surveillance cerne un nouveau genre de suspecte. Ces femmes deviennent une menace pour l'ordre républicain dans le contexte de mise en ouvre puis de stabilisation du régime de laïcité. L'ajustement de la surveillance à ce péril clérical féminin informe sur les transformations plus profondes de l'État et de la police politique.

\section{De la congréganiste à la militante, le nouveau péril clérical féminin ?}

\section{La loi de 1901, entre surveillance préfectorale et mise à distance de l'autorité religiense}

Depuis l'Affaire Dreyfus (1899), les droites françaises se sont recomposées. La structuration des partis politiques s'accompagne de la création de comités féminins. La reconnaissance légale du droit d'association ouvre des possibilités de regroupement et d'engagement collectif ${ }^{12}$. Les ligues de femmes catholiques qui se créent entre 1901 et 1902 adoptent donc le statut d'association selon la loi du 23 juillet $1901^{13}$. La loi vise d'abord à contrôler les congrégations religieuses qui doivent solliciter une autorisation en préfecture. Les congrégations, majoritairement féminines et dont les fondations furent nombreuses sous la Restauration ${ }^{14}$, passent ainsi sous le regard du Préfet. Nombre d'entre elles s'y refusent. Les religieuses sont sécularisées ou s'exilent en Belgique ${ }^{15}$. Leur statut de droit canonique posait problème à l'administration des cultes reconnus par le Concordat : ne dépendant pas de l'Évêque, mais de leur Supérieure, souvent sous tutelle des Jésuites ou d'un Ordre religieux, et placées sous l'autorité directe du Pape, les congrégations féminines bénéficient d'une relative autonomie vis-à-vis de l'Épiscopat et, par conséquent, de l'État qui avait un droit de regard sur la nomination des

9. Archives nationales (désormais AN) F7 12879 « Dames de l'Assomption».

10. AN F7 12719 «nationalistes - Action liberale populaire ", AN F7 12720 « Droite nationaliste », dossier Dames de la Patrie Française, AN F7 12721 «Ligue de la patrie française ».

11. AN F7 12717 «Complots monarchistes ».

12. Andrieu C., Le Béguec G., Tartakowsky D., (dir.), Associations et champ politique. La loi de 1901 à l'éprenve du siècle, Paris, Publ. de la Sorbonne, 2001.

13. Sarti O., The Ligue Patriotique des Françaises, 1902-1933: A Feminine Response to the Secularization of French Society, New York, Garland, 1992.

14. Langlois C., Le catholicisme au féminin Les congrégations françaises à supérieure générale an XIXe siècle, Paris, Cerf, 1985.

15. Cabanel P., Durand J.-D. (dir.), Le grand exil des congrégations religieuses françaises (19011914). Colloque international de Lyon, Université Jean-Moulin-Lyon-III, 12-13 juin 2003, Paris, Éditions du Cerf, 2005. 
évêques. A contrario, n'être déclarée que sous la forme d'association républicaine sans avoir d'existence en droit canonique offre une possibilité d'action en dehors du contrôle de la hiérarchie religieuse. C’est ainsi que les comités de la Ligue patriotique des Françaises, s'ils sont bien assistés d'un aumônier, n'ont pas de statut de droit canonique et n'ont aucune obligation formelle de rendre compte de leur activité à l'évêque diocésain ${ }^{16}$.

\section{Des ligues féminines pour la cause de l'Église : la Ligue des femmes françaises} (1901-1933) et la Ligue patriotique des Françaises (1902-1933)

L'affirmation d'une République indépendante de l'Église catholique débute dans les années 1880 et a pour point d'orgue la loi de Séparation des Églises et de l'État du 9 décembre 1905. La séquence qui s'ouvre avec la loi sur les associations et se clôt avec la Séparation est décrite par un courant historiographique catholique comme un moment de persécution religieuse et de haute conflictualité. Les inventaires des biens du clergé catholique ont donné lieu à des manifestations spectaculaires dans les paroisses de l'Ouest, voire à des affrontements dans deux paroisses catholiques du Faubourg SaintGermain ${ }^{17}$. Dans les Pyrénées, le montreur d'ours et son plantigrade enchâné nourrissent l'imaginaire catholique d'une République anticléricale et pourfendeuse de la religion populaire. Toutefois, l'ensemble des paroisses françaises est plutôt calme, suivant en cela une partie de l'épiscopat - les cardinaux verts - qui préféraient une «Église libre dans un État libre 18.

Certains catholiques voient dans la démocratie parlementaire un moyen légitime de faire avancer leur cause. La Ligue de la Patrie française ${ }^{19}$, l'Action libérale populaire (ALP) ${ }^{20}$ proposent ainsi de rassembler les catholiques nationalistes autour de la conquête des suffrages. Elles s'appuient sur des

16. Della Sudda M., «Entre protection et promotion d'un nouveau modèle d'engagement séculier. Les cardinaux protecteurs de l'action catholique féminine », in Jankowiak F., Pettinaroli L. (dir.), Les Cardinaux entre cour et curie. Une élite romaine (1775-2015), Rome, École française de Rome, 2017, pp. 125-137.

17. Joly L., "Les nationalistes et la loi de Séparation (1905-1906) », in Weil P. (dir.), Politiques de la laïcité an XX $X^{e}$ siècle, Paris, Presses Universitaires de France, 2007, pp. 99-121.

18. Déloye Y., Les Voix de Dieu. Pour une autre histoire du suffrage électoral, le clergé catholique français et le vote, XIXe-XXe siècle, Paris, Fayard, 2006.

19. La Ligue de la Patrie française est fondée le 31 décembre 1898 en réaction à la création de la Ligue des droits de l'homme. Patriote, elle se divise sur la question de la laïcité, certains membres optant pour une ligne libérale, d'autres pour une ligne nettement cléricale. Elle cesse son activité en 1910. Jules Lemaître, son directeur, et Gabriel Syveton sollicitent expressément des notables parisiennes pour bénéficier de l'appui du comité des dames chrétiennes en novembre 1901. Compagnie de Jésus (SJ), Archives de la Province de France, Fonds Pupey-Girard, «Ligue 1901-1906 », lettre de Marie Frossard, non datée ; Archives de l’Action catholique des Femmes, H565, « 1902 », «Entre le 4e et le 5e conseil », " Il est décidé et chacun approuve qu'on ne soutienne que les candidats acceptés à la fois par M. Piou et par Jules Lemaître ».

20. L'ALP est constituée d'un groupe de députés catholiques en 1901, elle dépose ses statuts d'association le 2 mai 1902 à Paris. Dirigée par Jacques Piou, elle s'appuie sur des comités électoraux qui recrutent essentiellement dans les milieux de notables catholiques. L'association cesse d'exister en 1919. 
comités électoraux masculins et sollicitent aussi la création de comités féminins. Ces derniers sont organisés sous l'égide d'épouses de notables ou de dames patronnesses. La Ligue des femmes françaises naît à Lyon à l'été 1901 à l'initiative de Jeanne Lestra, dont les proches sont royalistes, et de son directeur spirituel, le jésuite Antonin Eymieu 21. La fondation, appuyée par les jésuites, est suivie par la création d'un comité parisien de Dames chrétiennes à l'automne 1901. À Paris, le rôle de l'Évêché et celui du Provincial des jésuites sont déterminants : sollicités par le député Jacques Piou, qui anime le groupe de parlementaires catholiques de l'Action libérale populaire, ils enjoignent à des religieuses consacrées dans le secret, les Filles de la Société du Cour de Marie (Filles de Marie ou SFCM), de former l'armature militante des comités féminins ${ }^{22}$. Religieuses de la Société des Filles du cœur de Marie, dames patronnesses, épouses d'hommes politiques ou d'industriels, les femmes qui dirigent ces comités participent à la campagne des élections législatives du printemps 1902. Elles mettent au service de la cause de l'Église leurs ressources matérielles et symboliques, s'appuyant sur un capital social important.

Les femmes rassemblées dans ces ligues para-politiques se mobilisent pour la «quête électorale». Elles s'affrontent rapidement sur l'allocation des fonds aux candidats d'opposition au Bloc des gauches qui réunit les forces de gauche parlementaire pour les élections de 1902 : les Lyonnaises - royalistes soutiennent l'Action française, tandis que les Parisiennes sont proches de la Ligue de la Patrie Française et de l'ALP. Le dépôt des statuts de la Ligue libérale des Françaises a lieu le 21 mai 1902 à Paris, quelques semaines après celui des statuts de l'ALP. Le comité change de nom et prend celui de Ligue des femmes françaises comité de Paris le 26 mai 1902, puis celui de Ligue patriotique des Françaises (LPDF) en juin. Alliée à l'ALP, la LPDF se dote d'un réseau qui s'étend par capillarité paroissiale sur l'ensemble du territoire métropolitain. En 1905, la Ligue patriotique des Françaises revendique 150000 ligueuses ${ }^{23}$, des bibliothèques, des sociétés de secours mutuels - première forme d'assurance sociale -, des ouvroirs où les femmes pauvres effectuent des travaux de couture et de raccommodage, des secrétariats du peuple, des bibliothèques, etc. La scission porte avant tout sur une question politique, à savoir la légitimité pour les femmes catholiques de prendre part à la joute électorale. Elle cristallise la tension qui travaille alors l'ensemble du catholicisme dans les pays européens et fait l'objet d'un suivi attentif au Vatican et au sein de l'Épiscopat français. À la veille de 1914, la LPDF clame 500000 adhérentes, la Ligue des femmes françaises une centaine de milliers 24.

21. Dumons B., Les dames de la Ligue des femmes françaises (1901-1914), Paris, Éditions du Cerf, 2006.

22. Della Sudda M., «La politique malgré elles. Mobilisations féminines catholiques en France et en Italie (1900-1914) ", Revue Française de Science Politique, vol. 60, n 1, pp. 37-51. Archivio segreto Vaticano (désormais ASV), Segr. di Stato, 1914, rubr.12, fasc.19, "Lega patriotica delle donne francesi ». 
Les premiers rapports de police soulignent la proximité des comités de Dames avec le clergé. Tant par les causes qui les occupent que par les liens qu'elles entretiennent avec le clergé et les hommes catholiques engagés en tant que tels, les membres de la LPDF jouent un rôle de courroie de transmission entre le champ politique et le champ religieux via la Ligue, cette forme d'organisation para-politique ${ }^{25}$. La proximité de ces groupes féminins avec les partis pose question à l'administration républicaine. La police spéciale et la Préfecture de police de Paris indexent ainsi l'irruption des femmes catholiques dans le champ politique comme une transgression silencieuse des frontières entre des sphères séparées : électorale et religieuse/masculine et féminine. Cette note de la Préfecture de Police de Paris est transmise au Ministère de l'Intérieur et des Cultes pour l'informer de l'entremise du clergé dans les affaires politiques via la LPDF :

«En dehors des instructions qu'ils ont données à leurs prêtres au sujet des associations catholiques ayant pour objet de veiller au Denier du Culte, les évêques les ont autorisés à donner des conférences partout où ils le jugeront nécessaire, afin de faciliter la tâche de ces associations et de provoquer les offrandes des fidèles. Toutefois, les évêques ont recommandé à leurs prêtres de ne pas se mêler d'une façon trop ostensible à la politique militante et d'agir de préférence sur les ligues ou comités créés à côté des groupements politiques. C'est pour cette raison qu'à l'heure actuelle un grand nombre de prêtres offrent leur concours, comme conférenciers, à la Ligue des Femmes Françaises 26 ».

Régulièrement, des prêtres de différentes tendances, selon la sensibilité politique de la présidente de comité de la Ligue, interviennent auprès des adhérentes dans des conférences ou des «causeries ». Les ligues de femmes, parce que leurs membres n'ont pas le droit de vote, et parce qu'elles sont considérées comme «naturellement » éloignées des querelles partisanes, apparaissent ainsi comme un moyen de propagande efficace et discret pour reconquérir les électeurs sans attirer le regard de l'administration préfectorale.

23. «Comité central », Écho de la Ligue patriotique des Françaises, janvier 1905.

24. Le chiffre est le même que celui donné par la police spéciale.

25. Dogan M., Narbonne J.-F., Les Françaises face à la politique. Comportement politique et condition sociale, Paris, A. Colin, 1955. Voir également Vervaecke P., « La politique sans le parti. La Primrose League et la culture politique britannique, 1883-1919 », Politix, vol. 81, $\mathrm{n}^{\circ}$ 1, 2008, pp. 81-104 et Dieu, la couronne et l'empire, La Primrose League (18832000). Culture et pratiques politiques d'un mouvement conservateur, thèse de doctorat, université de Lille 3, 2003.

26. Archives de la Préfecture de police de Paris (désormais APPP) BA 902, Comité de Dames ALP-LPDF », note, sn, Paris le 12 septembre 1907, ms : «Classement 1er B/ Int cultes/ 188024 », « original classé à Chatenet 9205002 ». 
Derrière les militantes, se profile aux yeux des agents de la Sûreté l'influence des jésuites. L'installation de la Ligue dans l'hôtel particulier de sa trésorière, $\mathrm{M}^{\mathrm{me}}$ Potron, dont le fils est jésuite et animateur d'œuvres sociales, attire l'attention. L'aumônier de l'association, le Père Pupey-Girard, se voit attribuer - à raison - un rôle central dans l'organisation de la Ligue. En avril 1908, le Ministère de l'Intérieur demande à la Préfecture de police de Paris de lui fournir tous les renseignements sur la LPDF en vue de la tenue de son congrès ${ }^{27}$. Le rapport est remis par $\mathrm{M}$. Soullière, commissaire de police, à la Préfecture de police de Paris. Il témoigne d'une bonne connaissance de l'association et de l'inquiétude que suscite la compagnie de Jésus : «L'âme de cette association politico-religieuse est un ancien Jésuite, le Père PUPEYGIRARD, domicilié rue $S^{t}$ Honoré, 368, Camérier secret du Pape, grand ami de Mor Mantagnini [Montagnini], dont il a été l'un des meilleurs agents 28 ». Le rôle joué par les femmes de la Société des Filles du Cour de Marie n'est quasiment jamais évoqué. Pourtant, elles sont sous l'autorité des jésuites. La stratégie de l'Archevêque de Paris et de R. Pupey-Girard de les solliciter pour monter des comités électoraux féminins afin de passer au travers des fourches caudines de l'administration préfectorale semble donc fonctionner.

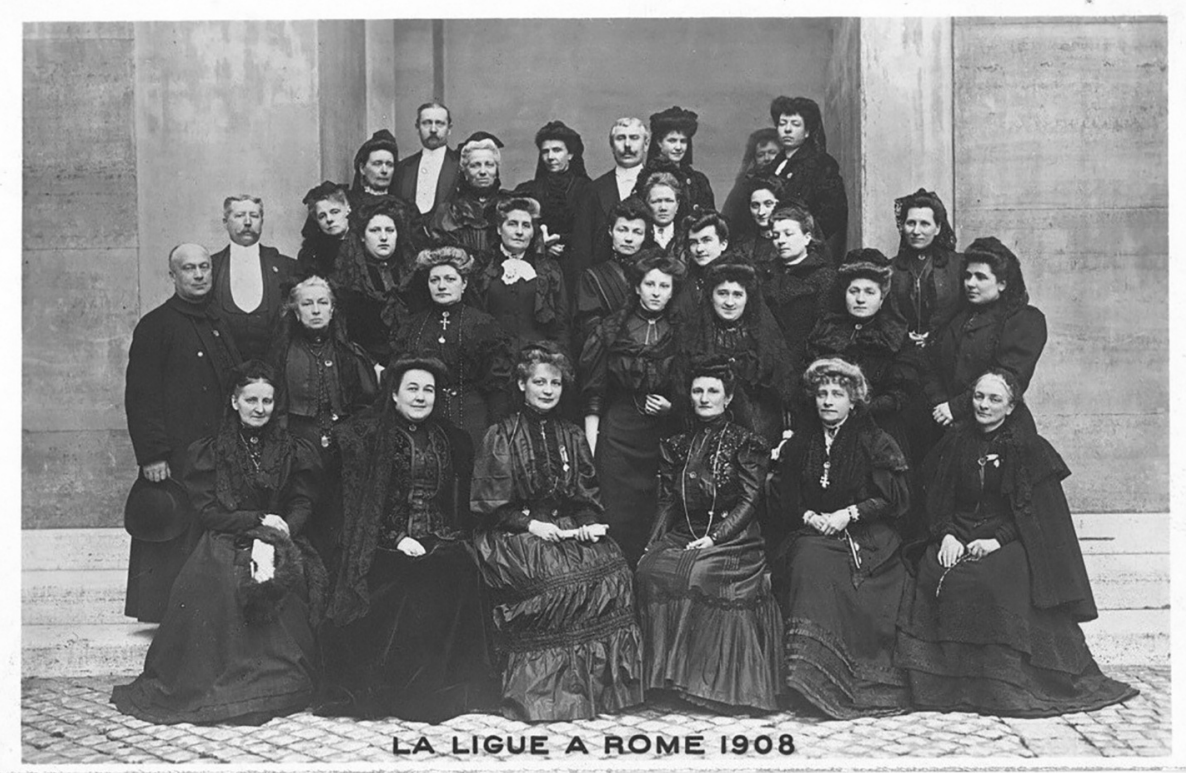

La Ligue à Rome (Archives de I'Action catholique des femmes, H712)

27. APPP, APPP, BA 902, Comité de Dames ALP-LPDF, Cabinet, 1er bureau, n¹8850-24, « Note pour Monsieur le Directeur général des recherches », Paris, le 30 avril 1908. « Ces renseignements sont demandés d'extrême urgence par le Ministère de l’Intérieur ». 
Ce rapport rédigé à la veille des élections législatives de 1910 rend compte de l'influence des jésuites sur la campagne électorale. Il souligne d'une part la présence de femmes aux côtés des partis catholiques, leur implication dans les modalités mêmes d'accomplissement du suffrage - et d'autre part, le rôle des jésuites dans la mobilisation féminine :

«Rappelons que la Ligue Patriotique des Françaises, dont la présidente est la baronne Reille, et qui eut longtemps comme sous-titre 'Action libérale populaire' est entièrement sous l'influence des Jésuites. Elle a pour aumônier-conseil le P. Pupey-Girard, homme fort intelligent et d'une très grande activité ; et ses principaux conférenciers sont : les P.P. de Penfentenyo, Potron, Loiseau de Grandmaison, Lemarescal, qui tous appartiennent à la compagnie de Jésus 29 \%.

Apparaît ainsi le second registre des représentations genrées qui orientent le regard des agents de la Surreté : des femmes sous influence cléricale - l'internationale noire - et, par voie de conséquence, aux ordres d'une puissance étrangère.

\section{Des femmes au service d'une puissance étrangère : le bras armé féminin $d u$ Souverain-Pontife}

L'influence cléricale et religieuse à laquelle les femmes seraient soumises, par nature, les placerait dans un conflit de loyauté depuis la Séparation : comment choisissent-elles entre leur nation et leur foi ? Peu après la crise diplomatique de 1904 entre le gouvernement français et le Saint-Siège, la présidente de la Ligue, la baronne de Brigode, et $\mathrm{M}^{\mathrm{me}}$ de Bournonville, Présidente du Comité de Versailles, toutes deux membres de la Société des Filles de Marie, se rendent à Rome. Elles font l'objet d'un rapport le 13 mars 1905 qui attire l'attention sur la rencontre entre ces dirigeantes et l'ancien nonce, le cardinal Lorenzelli, «auquel la Ligue patriotique des Françaises a demandé des instructions au sujet de la Séparation des Église et de l’État 30 ». En dépit de la position libérale de l'association, leur ultramontanisme inquiète. Il est pointé par cet informateur qui écrit sur un papier à en-tête d'Ostende (Belgique) :

« La LPDF est cléricale, uniquement cléricale. Certes on ne saurait dire que les femmes qui la composent manquent de patrio-

28. APPP, BA 902, Comité de Dames ALP-LPDF, Commissaire Soullière, Préfecture de Police, DG des Recherches, 1re Brigade, Cabinet, 1er Bureau, n 18 850-24 « Au sujet de la Ligue Patriotique des Françaises ", ff.3.

29. AN, F7 13215, F 5083 Paris, le 29 avril 1910, « La Ligue patriotique des Françaises et les élections » (copie de la Préfecture de police de Paris).

30. APPP, BA 902, Comité de Dames ALP-LPDF, ms: Fischer 18850-24, Paris, le 13 mars 1905, dact. 
tisme, qu'il faut même admettre que dans les sections de province notamment des adhérentes sont venues attirées par la magie de ce vocable, mais les dirigeantes sont avant tout cléricales, sont avant tout romaines. C'est de Rome que leur viennent toutes les approbations, toutes les directions, tous les mots d'ordre et si ces dames avaient à choisir entre le désir du pape et le veto de M. Poincaré, bien que leurs frères, leurs maris ou leurs pères aient tous voté pour le Président actuel, aucune d'elle n'aurait la moindre hésitation : Pie X serait écouté D’ailleurs n'est-il pas infaillible !? 31 ».

Cette allégeance à la puissance étrangère n'est pas sans rappeler l'une des catégorisations de la violence politique des «femmes sous tutelle 32 ». Mais elle ne se réduit pas au genre. Cet argument est fortement mobilisé, à la même époque, dans les dossiers des anarchistes. Toutefois, pour les femmes, cette catégorisation est congruente avec leur statut de mineure et le soupçon de manque de libre-arbitre qui pèse sur elles en tant que femmes et en tant que catholiques. Si elles sont mal ralliées à la République, c'est qu'elles obéissent à une puissance étrangère, tout à la fois surnaturelle et temporelle, celle de l'Église. En avril 1908, le voyage à Rome de la secrétaire, Marie Frossard, de la Présidente, la Baronne Reille, et de l'aumônier, le Père Pupey-Girard, est suivi avec attention par la Sûreté. Les dirigeantes de la Ligue veulent l'approbation pontificale de leur action ${ }^{33}$. Le rapport du Commissaire Soullière au Ministère de l'Intérieur (02/05/1908) pointe le rôle d'agent de renseignement que joue l'aumônier. Les documents des archives vaticanes confirment sa fonction d'informateur auprès du cardinal Carlo Montagnini (1863-1913), auditeur de la nonciature puis « gardien des archives » expulsé le 11 décembre $1906{ }^{34}$. L'inquiétude à l'égard de la puissance étrangère et du renseignement extérieur est patente dans l'annotation qui est portée au dossier de la Sûreté « F7 13215/5/ demoiselle Weiller épouse Hervé », dans un rapport du 13 mai 1914, on trouve une mention manuscrite : «faire extrait pour dossier Lazare Weiller » et mention manuscrite en rouge : "Lazare Weiller est le cousin du général Gonse doit être diplomate ». Le général Gonse, alors réserviste, fut sous-chef d'État-major. Compromis dans l'Affaire Dreyfus, il est progressivement mis sur la sellette par le gouvernement Waldeck-Rousseau puis Combes ${ }^{35}$. On semble redouter que cette militante puisse avoir des liens avec la diplomatie à une époque d'intense activité de renseignement.

31. AN F7 13215, lettre manuscrite, sd, sn Hôtel du Casino, Ostende, ff.1. vers 1912-1913.

32. Cardi C. et Pruvost G., «Introduction générale. Penser la violence des femmes : enjeux politiques et épistémologiques », in Cardi C., Pruvost G., (dir.), Penser la violence des femmes, Paris, La Découverte, 2012, pp. 13-64.

33. APPP, BA 902, Comité de Dames ALP-LPDF, ms : Chastenet/ Sté, note du 8 avril 1908, copie dact.

34. ASV, Seg. di Stato, anno 1907, rubr.248, fasc.2, n¹791. Lettre anonyme et non datée qui figure dans une liasse de documents avec des renseignements fournis par Jacques Piou, pénitent de Pupey-Girard, au sujet du rôle des Filles du Cœur de Marie dans la LPDF. Montagnini sollicite le maintien des Filles de Marie dans la Ligue en dépit de nombreuses 
Le danger que peuvent représenter des militantes est d'autant plus grand que les catholiques libérales, ralliées à la République, sont aussi des membres de la bourgeoisie industrielle - Schneider, de Wendel, Potron. Certaines jouissent d'une certaine influence, comme Germaine Féron-Vrau, patronne d'usine et épouse du directeur de $\mathrm{La}$ Croix. Elles professent leur obéissance aux directives pontificales et se veulent les " auxiliaires dociles et zélées du clergé ». L'inquiétude du commissaire spécial de Marseille pointe dans son rapport au préfet des Bouches-du-Rhône

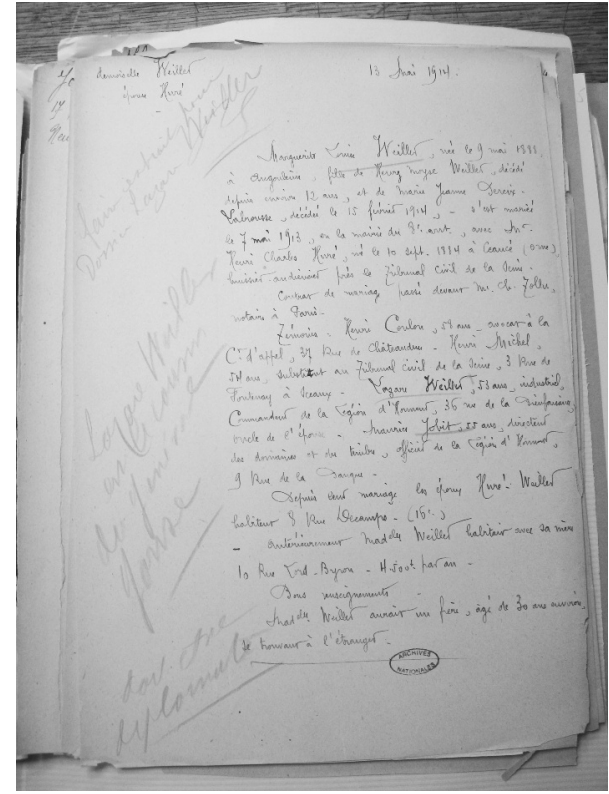

Fiche de renseignement annotée sur Mme Louise Weiler (AN F7 13215/5/). quand il rapporte les propos d'un jeune avocat qui tient une conférence auprès des femmes de la Ligue. L'évêque, présent à ce congrès local, « a affirmé que les catholiques de France sont plus unis, plus ardents que jamais, et soumis très respectueusement aux ordres des évêques et du Souverain Pontife 36 ».

Femmes et catholiques, les membres de l'association sont ainsi renvoyées à une altérité politique qui est de nature quasi-ontologique : par leur sexe, par leur foi et par leur loyauté à une puissance étrangère.

\section{Une menace pour la République : l'influence des femmes sur les électeurs}

\section{Des ligues féminines réactionnaires}

Si ces groupes font l'objet d'une surveillance, c'est parce qu'on leur prête la capacité de déstabiliser le régime républicain. Les premiers rapports et notes de surveillance font état de la propension réactionnaire de ces groupes de «Dames de l'Action libérale populaire ». Le comité de «Dames chrétiennes »

plaintes au sujet de leur engagement politique, ASV, Seg. di Stato, anno 1907, rub.248 n $^{\circ} 17691 / 17682$, du Card. Montagnini au Card. Merry del Val, Paris, le 18 mai 1906.

35. Laurent S.-Y., Politiques de l'ombre. État, renseignement et surveillance en France, Paris, Fayard, 2009.

36. AN F7 13217, Bouches-du-Rhône, Ministère de l'Intérieur, Commissariat spécial près la Préfecture, n³38 « Ligue patriotique des Françaises - Conférence de Me Gerlier Duplicata », Rapport, Marseille, le 27 janvier 1913, ff.1. 
qui organise la manifestation « Des mères de famille » du 27 juillet 1902, est ainsi signalé dans un rapport que l'on retrouve à la Sûreté et à la Préfecture de police de Paris ${ }^{37}$. Des sections féminines voient le jour dans différentes organisations de droite. Des femmes prennent part aux comités électoraux JusticeÉgalité fondés en 1896 pour financer les candidats catholiques aux législatives de 1898 38. La Ligue de la Patrie Française de Jules Lemaître a son Comité de Dames ${ }^{39}$, tout comme l'Action Libérale populaire. L'Action française crée ses sections féminines en 190440 et des Dames royalistes participent à la fondation de la Ligue des femmes françaises à Lyon ${ }^{41}$. Parmi ces groupes, la Ligue patriotique se distingue par son implantation et par son positionnement politique : "La Ligue Patriotique des Françaises poursuit un triple but : action sociale, apostolat religieux et propagande réactionnaire, et seconde ainsi les efforts de 'l'Action libérale populaire' 42 ». Ce terme qui renvoie très clairement à la contestation de la République, est aussi utilisé par d'autres agents de la Police spéciale, tel ce rapport du Commissariat spécial de Troyes (Aube), du 14 novembre 1913 : «Une dizaine de dames de Bar sur Aube très connues pour leurs idées réactionnaires et religieuses y assistaient. On a remarqué à une de ces réunions la présence de Mme Piot chatelaine [sic] à Lignol 43 ». La présence de la châtelaine témoigne d'un rapport de patronage encore prégnant dans les villes de province, attestant de processus de politisation marqués par l'encastrement des activités sociales et politiques.

Le contexte de fortes mobilisations sociales peut aussi susciter une vigilance plus attentive sur les groupes de droite soupçonnés de préparer un retour à l'ordre. Cette crainte quant à l'entourage des Ligueuses et au risque de sédition est patente dans un rapport de la Préfecture de police qui fait état de la présence à la réunion de la LPDF « des députés, des hommes politiques et plusieurs officiers supérieurs en activité ». Le rapport évoque une préparation «à quelque action qui pourrait être formidable si une entente se faisait », entre les groupes conservateurs de la Seine ${ }^{44}$. C'est parce qu'elles peuvent

37. AN, F7 12720 droite nationaliste, dossier « Dames chrétiennes », sn, sd, 15 août 1902, ff.n71; ms en marge du paragraphe « particulièrement dans les grands quartiers et à se diriger ensuite comme à un lieu de pèlerinage, aux abords des écoles fermées. » : «Des dispositions discrètes de surveillance aux abords des écoles ont été prises ".

38. Les comités sont clairement anti-dreyfusards, présidés par Paul Féron-Vrau (1896), directeur de la Croix (1900), le quotidien des Assomptionnistes, puis par le baron Jean-Pierre Raymond de la Rocque. Ils rassemblent des clercs et des laïcs. En 1900, l'aile conservatrice emportée par Féron-Vrau, Michel de Bellomayre et Louis Laya, qui sera un conférencier régulier de la LPDF, fait scission. Huard, R., La naissance du parti politique en France, Paris, Presses de la Fondation nationale des sciences politiques, 1996, pp. 252-253.

39. Rioux J. P., Nationalisme et conservatisme : la Ligue de la patrie française, 1899-1904, Paris, Éditions Beauchesne, 1977.

40. Cléret C. «De la charité à la politique. L’engagement féminin d'Action française ", Parlement [s], Revue d'bistoire politique, vol. 19, n 1, pp. 17-29.

41. Dumons B., Les dames..., op.cit.

42. APPP, BA 902, Comité de Dames ALP-LPDF, Commissaire Soullière, Préfecture de Police, DG des Recherches, 1re Brigade, Cabinet, 1 ${ }^{\text {er }}$ Bureau, n 18 850-24 «Au sujet de la Ligue Patriotique des Françaises ", ff.1.

43. AN, F7 13216. 
fédérer autour d'elles des hommes de différentes tendances, et en particulier les officiers, qui mirent peu d'empressement à faire appliquer les lois de la République, que les conférences de la Ligue sont ainsi surveillées.

La proximité avec l'Action française est soulignée par le commissaire spécial de Marseille. On repère également, annotée en bleue, la mention manuscrite du destinataire d'un rapport sur une conférence de Me Gerlier, avocat et président local de l'Association catholique de la jeunesse française : « RS m'en parler C'est l'union de la LPDF et de l'ACJF Jaune 45 ». En effet, en dépit du conflit qui oppose les libérales de la LPDF aux royalistes de l'Action française, certains agents soulignent le caractère pernicieux d'une adhésion formelle à la République chez les femmes catholiques. Ainsi, le commissaire spécial Mounin, après avoir expliqué les rapports de la LPDF avec l'Action Libérale Populaire et l'Action Française n'en attire pas moins l'attention de la Préfecture :

«Au cours du Congrès, il n'a été prononcé aucune parole contre le régime républicain, pas plus par les congressistes que par les Prélats ; les royalistes ne se sont nullement préoccupés de ce congrès; leurs sympathies ne vont pas à ce groupement, qui comprend des femmes de toutes les nuances politiques, mais aux "Dames de France”, qui ne comprennent que des Royalistes. La LPDF, dont les dirigeantes ne se préoccupent en apparence que des intérêts de la Religion et de la Patrie, en laissant entièrement de côté les questions d'ordre politique, n'en est peut-être que plus dangereuse. Tout se fait par la douceur et la persuasion dans cette ligue, dont les statuts indiquent qu'elle n'aura recours qu'aux moyens légaux, mais aucune des 3000 personnes qui ont assisté à la conférence qu'a faite Me Ménard, député de Paris, pour clôturer les travaux du Congrès, n'a protesté lorsque l'orateur recommanda à ses auditeurs de ne reculer ni devant l'émeute ni devant la mort pour “sauver la France”. En tous cas, l'organisation de la LPDF, ses moyens d'action et ses progrès, méritent, à mon avis d'attirer l'attention. Les personnes qui la dirigent n'ont certainement pas de grandes sympathies pour la forme actuelle du Gouvernement et elles sont, d'autre part, trop avisées pour montrer qu'elles aspirent au rétablissement de la monarchie de droit divin 46 ».

44. APPP, BA 902, Comité de Dames ALP-LPDF, «ms : Vetiver - 1880-24 », 15 avril 1906, dact.

45. AN F7 13217 Ministère de l'Intérieur, Commissariat spécial près la Préfecture, $\mathrm{n}^{\circ} 338$ « Ligue patriotique des Françaises - Conférence de Me Gerlier - Duplicata », Rapport, Marseille, le 27 janvier 1913.

46. AN F7 13217 Ministère de l’Intérieur, Commissariat spécial près la Préfecture, nº 769 « Ligue patriotique des Françaises - Confidentiel Duplicata », Rapport, Marseille, 23 février 1911, papier et papier carbone dact. 
Particulièrement attentif aux développements de l'association, le commissaire marseillais transmet des rapports soignés à la Préfecture sur cette ligue qui compterait 10000 adhérentes à Marseille, 1200 à Aix. L'association recrute dans tous les milieux sociaux, dirigée par les femmes notables de ces villes. L'adhésion tacite des femmes aux propos de l'avocat appelle la suspicion et laisse entendre que les catholiques seraient prêtes au coup de force contre la République. La douceur et la persuasion des femmes catholiques sont présentées comme une manière habile de masquer l'hostilité au régime républicain. Le mode d'action obéit au registre habituel de [dis]qualification du pouvoir des femmes. Invisible et latente, cette subversion féminine et religieuse vient justifier la surveillance resserrée.

\section{Surveillance des incursions féminines dans le champ politique}

À côté de la violence potentielle qu'elles pourraient exercer sur la voie publique, comme lorsqu'elles envisagent de manifester lors de la discussion du projet de loi Briand sur la Séparation ${ }^{47}$, les femmes font l'objet d'une surveillance en raison de leur incursion dans l'arène électorale masculine. On redoute une intrusion féminine faussant la compétition électorale par ses subsides ou son influence. Un agent de la Préfecture de police de Paris, relate ainsi les propos tenus aux femmes par Jacques Piou, président de l'Action libérale populaire, lors de la réunion privée de la Ligue du 16 février 1906 : «Il invite les femmes à user de leur influence pour les élections prochaines et à faire de la propagande en faveur des catholiques. Pour cela il recommande l'emploi du bulletin de vote seul moyen de se débarrasser des sectaires, des antimilitaristes et des antipatriotes 48 ». L'abbé Coubé, connu pour ses saillies anti-francmaçons, abonde dans ce sens : « comme M. Piou, il engage la femme à se mêler à la bataille électorale 49 ». À la fin de la réunion, "plusieurs adhérentes de la Ligue patriotique des françaises, sont chargées de faire circuler des listes de souscription, dont le montant servira à couvrir les frais des élections 50 ». Deux jours plus tard, une réunion des sections parisiennes qui rassemble 2500 femmes fait l'objet d'une surveillance qui relate les propos de Mlle de Valette, conférencière et membre du Conseil central de l'association, particulièrement véhémente contre les francs-maçons :

47. APPP, BA 902, Comité de Dames ALP-LPDF, «ms: Fischer - 18850-24 », Paris, le 24 mars 1905. «Ces dames ne regarderont pas à la dépense, voulant faire une manifestation imposante. Elles sont décidées à embaucher des individus qui ne craignent rien. »

48. APPP BA 902, Rapport 1er bureau, «Réunion privée de la Ligue patriotique des Françaises », 17 février 1906, dact., ff.2.

49. APPP BA 902, Rapport 1er bureau, « Réunion privée de la Ligue patriotique des Françaises », 17 février 1906, dact., ff.2. L'agent poursuit : «Il traite les agents du fisc de cambrioleurs de sanctuaires, rend hommage aux victimes des églises Ste Clotilde et Gros-Caillou et fait l'éloge des fidèles qui ont répondu à l'appel. À son avis, la loi est impie, lui obéir est un crime, et refuser un devoir ». Il invite à financer la campagne: «Il faut semer des pièces d'or et des billets de banque ».

50. Idem. 
«Elle fait appel aux femmes françaises et demande qu'elles ne se laissent pas traiter en parias par les ennemis de toutes nos libertés. Pour cela, il est nécessaire d'avoir de bonnes lois, et pour faire ces lois, il fait de bons députés, d'où elle déduit que les femmes doivent s’immiscer dans la question des élections, sinon par le bulletin de vote, du moins par leurs conseils éclairés en désignant à leurs maris et à leurs fils ou frères les candidats honnêtes loyaux et sincères 51 ».

L'influence des femmes sur les esprits masculins de leur famille est présentée de manière positive par les catholiques. Les agents ne sont pas tous convaincus par cette argumentation, même si elle vient étayer l'intérêt de leur rapport aux yeux de leurs supérieurs. Ce rapport de la Préfecture de police de Paris explique de manière plus prosaique l'influence exercée par les dames de la Ligue sur les jeunes gens des Jeunesses catholiques, de l'Avant-garde royaliste, des Volontaires de la Liberté ou des Militants du Devoir chrétien : «L'enthousiasme des jeunes gens vient de ce qu'ils sont poussés par les femmes et que beaucoup espèrent y trouver l'occasion de mariages à grosses dots $52 »$.

Dans les rapports des agents de la Sûreté ou de la police, le rôle des femmes sur les électeurs est évoqué comme une menace. Courroie de transmission entre le clergé et l'électeur, elles obèrent le libre exercice du suffrage par les citoyens. Les élections de 1902 ont pour enjeu l'application des décrets et la fermeture des écoles congréganistes. Un rapport de la Sûreté fait état de l'opinion dans sa circonscription alpine :

«Il n’est pas en Maurienne, une femme fréquentant l'Église, un enfant allant au catéchisme, une fillette élève des religieuses qui ne dise à son mari, à son père, qui n'ait répété pendant la période électorale, que si les Francs-Maçons (alias Deléglise) étaient élus, les enfants ne feraient plus leur première communion, les églises seraient fermées, les prêtres chassés... ${ }^{53}$ ».

Les législatives de 1906, qui font suite à la loi sur la séparation sont présentées comme le moyen légal de la revanche pour les catholiques. La mort de Régis André, blessé en s'opposant aux inventaires des biens du clergé, le 24 mars 1906, est saisie par les opposants pour montrer la férocité de la police républicaine. Les protestations consécutives entraînent un surcroît de surveil-

51. APPP, BA 902, sn, 1er Bureau, Rapport sur la Réunion organisée par la Ligue patriotique des Françaises, sections des 3 e, 4 e, $5^{\mathrm{e}}$ et $12^{\mathrm{e}}$ arrondissements », 19 février $1906 \mathrm{ff} .2$.

52. APPP, BA 902, Comité de Dames ALP - Fischer, note de Paris, 28 février 1906, dact. Il précise à cette occasion qui est son informateur : «M. Deneu de Montbrun, architecte, rue Lauriston, qui fait partie de plusieurs de ces groupes », qui voit dans la protestation contre la Séparation la main de la LPDF et explique l'influence par l'attrait de la dot.

53. AN F7 12721, Ligue de la Patrie Française, Rapport d’E. Baudot, sûreté générale St Jean de Maurienne, 9 mai 1902. 
lance où l'on voit collaborer étroitement les différents services de police à Paris. Les rapports témoignent d'une activité importante en Province, confirmée par les archives de la Ligue patriotique des Françaises. Ainsi, dans les Deux-Sèvres, la conférence observée par le correspondant de la Sûreté témoigne de l'action électorale qui vise à faire pression sur les électeurs :

\begin{abstract}
«La préparation des bonnes élections. La femme doit user de toute son influence - souvent considérable sur certains caractères - pour décider les siens à voter contre les partisans du 'bloc' et à appuyer de leurs bulletins le candidat de la protestation. "La femme doit se souvenir, qu'au jour du jugement dernier, Dieu demandera compte de leurs votes, aux maris et aux frères et condamnera sévèrement la femme qui n'aura pas su être assez éloquente, ou n'aura pas usé de toute son influence pour forcer ses proches à voter pour le candidat de Dieu. (Rigoureusement exact)" [sic.]. Cette campagne, menée en ce moment par la presse religieuse, les conférenciers et conférencières catholiques, est poussée plus activement encore et avec une énergie désespérée par les prêtres, dans l'ombre du confessionnal et à l'abri de la sacristie. On se rejette sur les femmes, filles et mères des électeurs, - espérant que celles-ci, par croyance personnelle par soumission ou par crainte - feront au foyer la campagne que l'on n'ose mener au grand jour. Tous les arguments sont mis en avant pour peser sur l'esprit de ces malheureuses. On leur demande de faire des leurs des 'convaincus' qui s'en iront ensuite au bureau, au café, au marché de la ville, prêcher à leur tour la bonne parole [...] On y joue de tous les sentiments et on appuie sur toutes les cordes. C'est un mouvement général qui s'est étendu sur toute la France, presque subitement, et qui semble procéder d'un mot d'ordre mystérieux et secret. Partout, en ce moment, se poursuit un programme de résistance et de propagande "par la femme" qui, seule, peut décider les hommes faibles et les caractères indécis à "taper sur le groin de la bête maçonnique et à combattre le sordide bonnet rouge, emblème de la servitude” 54 ».
\end{abstract}

La dernière phrase du rapport révèle l'inquiétude face au risque de renversement de la hiérarchie du genre : les femmes, conservatrices et anti-républicaines, prennent l'ascendant sur les hommes tièdes, et imposeraient ainsi leur voix dans la compétition électorale. Si besoin, elles pourraient avoir recours à des moyens utilisés jadis par les femmes d'Athènes pour décider leurs hommes au combat : "On affirme même que pour arriver à les y contraindre, $M^{\text {lle }}$ Dijon qui ne manque pas de hardiesse, avait été jusqu'à conseiller le recours au procédé qu'Aristophane prête à Lysistrata 55 ». Le refus d'accomplir le « devoir conjugal » serait ainsi l'ultime moyen pour convaincre les maris

54. AN, F7 13 218, Deux-Sèvres, Rapport, Arnaud, 2 avril 1906, dact. non signé, ff.3. 
républicains de voter pour le candidat catholique. Enfin, dernier registre de l'influence, ces femmes, anciennes congréganistes ou paroissiennes zélées, font inscrire les pensionnaires des hospices et les accompagnent voter, non sans avoir établi la continuité de la foi avec le vote : "Nous tenons de source sûre qu'on s'occupe beaucoup des élections législatives à la Ligue patriotique des Françaises. Dans une des dernières réunions des dirigeantes tenue au siège social, 368, rue Saint Honoré, on a commenté un passage du catéchisme de Mgr où il est dit que c'est une faute de ne pas voter; et il a été rappelé aux adhérentes la responsabilité des femmes à cet égard. À la même réunion il a été dit qu'à Levallois on a fait inscrire aux listes électorales les vieillards des Petites Sœurs des pauvres 56 ».

Si tous les rapports ne vont pas aussi loin dans la description de la menace, les incursions féminines dans le champ électoral sont signalées.

\section{Surveiller sans punir : dispositifs de surveillance des femmes catholiques}

\section{Préfecture de police de Paris et Sûreté générale, une surveillance croisée}

Au début du XXe siècle, le territoire métropolitain fait l'objet d'un double dispositif étatique de surveillance politique. D’une part, la Police spéciale des chemins de fer, en dépit de son nom, est chargée de la surveillance sur l'ensemble du territoire national à l'exception de Paris, qui prend le nom en 1911 de police spéciale. Héritée du Second Empire 57, elle est conservée par la République pour surveiller d'abord les anarchistes (1893-1894) et, avec l'Affaire Dreyfus, les nationalistes. À partir de 1907, un service des archives rassemble les innombrables fiches sur les individus suspects de troubler l'ordre républicain. À Paris, la surveillance échoit à la Préfecture de police, dirigée à l'époque qui nous intéresse par les préfets Louis Lépine, puis Célestin Hennion ${ }^{58}$, qui en 1913, sépare la police judiciaire des Renseignements généraux et des jeux par la création de deux directions distinctes. Le premier doit sa nomination à sa proximité avec le président du Conseil, WaldeckRousseau, qui l'appelle après l'agression du Président de la République, Émile Loubet, par un militant monarchiste et antidreyfusard le 4 juin 1899. Le second, républicain et membre de la police spéciale, spécialiste de la surveillance des milieux anti-républicains de droite, est un homme de réseau proche de Clémenceau. La $2^{2}$ section de la DRG est spécifiquement dédiée aux partis et groupuscules de droite. Une partie des fonds éparpillée par les vicissitudes de l'histoire et la surveillance politique de l'entre-deux-guerres, est partiellement accessible dans le Fonds de Moscou (Fontainebleau).

55. AN, F7 13 216, Préfecture du Doubs, Besançon, le 30 avril 1912.

56. AN F7 13215, F 5083 Paris, le 29 avril 1910, La Ligue patriotique des Françaises et les élections.

57. Laurent S.-Y., Politiques de l'ombre..., op.cit, pp. 71-sq.

58. AN F7 13218, Paris XXe, formulaire vierge, «République française », « Nous Hennion... » 
Les éléments glanés font l'objet de rapports transmis en plusieurs exemplaires et classés dans différents dossiers. Les indications du travail routinier de surveillance, qui consiste pour partie à lire et archiver, sont variables en fonction des préfectures et du zèle des agents, ainsi que du degré de politisation des questions religieuses ${ }^{59}$.

La Préfecture de police de Paris témoigne d'un suivi précoce des comités de femmes catholiques. Les tensions héritées de l'Affaire Dreyfus sont encore présentes dans les esprits et les ligues nationalistes font l'objet d'une surveillance accrue depuis l'épisode de Fort-Chabrol d'août 1899, qui vit Jules Guérin et les nationalistes narguer les forces de l'ordre en se retranchant dans l'immeuble du journal L'Anti-Juif ${ }^{60}$. Sollicitée pour faire partie du comité parisien de la Ligue en 1901, Mme d'Hautpoul refuse d'entrer à la direction, s'estimant trop liée aux Comités Justice et Égalité, ce qui attirerait l'attention de la Sûreté. La victoire du bloc des gauches en 1902 et la poursuite de la politique de laïcité par le gouvernement Combes fédère les nationalistes et les catholiques à l'été 1902. La manifestation des Mères de familles du 27 juillet à la Concorde est le point de rendez-vous des différentes droites - nationaliste, royaliste et catholique - pour la défense de la famille et de l'enseignement confessionnel. La préfecture de police de Paris surveille les organisatrices avec attention. Si les fiches individuelles des femmes ont toutes été détruites ${ }^{61}-\mathrm{à}$ l'exception des fonds versés par les Archives nationales -, on conserve néanmoins des documents relatifs aux associations, aux manifestations et à la mise en application des lois de 1901 sur les associations et de 1905, dans lesquels les femmes apparaissent comme des protagonistes de la contestation religieuse.

Ces périls sont à mettre en relation avec l'intensification du dispositif de surveillance politique qui se modernise durant les premières décennies de la République. Une grande partie du travail quotidien des agents de la Sûreté consiste à dépouiller la presse ${ }^{62}$. À la préfecture de police de Paris tout comme dans les fonds des Archives nationales (Ministère de l'Intérieur et des cultes), les liasses indiquent un dépouillement minutieux des quotidiens de toutes tendances politiques. Mais les agents sont aussi présents dans les manifestations

59. Sur la routine et les catégories ordinaires de fonctionnement voir le travail précis de Bayon N., «Personnels et services de surveillance de la préfecture de police : de la constitution des dossiers de surveillance à la mise en forme du politique (1870-1900) », Cultures E Conflits, n 53,2004 , [En ligne], DOI : 10.4000/conflits. 997.

60. Berlière J.-M., Naissance de la police moderne, Paris, Perrin, 2011.

61. Parmi ces fiches individuelles, un certain nombre font état de renseignements erronés, tels la fiche de $\mathrm{M}^{\mathrm{lle}} \mathrm{H}$. Ballot, établie le 2 mai 1914, qui ne réside pas à l'adresse indiquée et aux alentours (l'Institut de la Tour dit ne pas la connaître). Il en va de même pour la demoiselle Ferbié, « inconnue 13 rue des Sablons, où se trouve un hôtel meublé » et qui n’a pas logé dans ce meublé depuis quatre ans. M ${ }^{\text {lles }}$ de Nayville, Morault, Denise Leclercq sont également introuvables aux adressés indiquées (66, rue du Cherche-Midi, 68bis rue du Cherche-Midi et 113 Bd Saint Germain). On peut s'interroger sur la discontinuité de la surveillance qui pourrait être liée à une perception amoindrie de la menace cléricale.

62. Bayon N., "Personnels et services de surveillance... ", op. cit. 
publiques : la rue, les abords des salles de conférence, les réunions publiques et plus rarement des informateurs assistent aux conférences privées ${ }^{63}$. La surveillance des femmes dans des lieux où les hommes sont incongrus, sauf à revêtir l'habit ecclésiastique, représente une gageure.

\section{Informateurs et agents républicains}

La particularité des milieux conservateurs observés - femmes et hommes de la grande bourgeoisie, notables catholiques, salons, espaces privés tels que les maisons générales de congrégations - implique des modalités de renseignement spécifiques. Comment assister à des réunions privées, telle celle du 13 décembre à Niort, à laquelle «ne pouvaient assister que les personnes qui avaient reçu une carte d'invitation 64 » ? À une époque où la police est entièrement masculine, le recours à des informatrices est nécessaire. Ainsi que le faisait remarquer le préfet de police de Paris de 1879 à 1881, Louis Andrieux, républicain libéral que l'on retrouve aux côtés des catholiques dans la manifestation de juillet 1902 :

«Ce n'est pas toujours l'importance du service rendu qui en détermine la quotité ; il n'en coûte pas cher de faire surveiller les anarchistes, les collectivistes et tous les apôtres de la révolution sociale : mais les agents qui travaillent dans les salons ont des exigences relativement exagérées pour les services qu'on en tire 65 ».

Trouver les indicateurs, s'assurer de leur fiabilité et les rétribuer, voilà une tâche ardue à laquelle la Sûreté générale est confrontée. «L'agent secret », rappelle Andrieux « se recrute dans toutes les couches sociales : c'est votre cocher, c'est votre valet de chambre, c'est votre maîtresse, ce sera vous demain, pour peu que la vocation vous prenne, à condition toutefois que vos prétentions n'excèdent pas vos mérites, car ceux qui sont à vendre ne valent pas tous la peine d'être achetés 66 ». À ce jour, les recherches entreprises à la Préfecture de police de Paris n'ont pas permis d'identifier les personnes susceptibles d'avoir surveillé les catholiques. Seul un indicateur a échappé à l'oubli. Dans le carton BA 902 Comité de dames ALP-LPDF, on trouve une enveloppe adressée à « Monsieur Lépine », «personnellement à son cabinet de travail 67 ». Dans un

63. Sur les différences juridiques entre réunion privée et publique, et ses implications sur la surveillance, voir Cossart P., Le Meeting politique de la délibération à la manifestation (18681939), Rennes, Presses universitaires de Rennes, pp. 78-81.

64. AN F713218 Commissariat de police, Niort, à Monsieur le Directeur général de la Sûreté générale à Paris, Niort, le 14 décembre 1908, dact. signé.

65. Andrieux L., Sonvenirs d'un Préfet de Police, t.1, Paris, Jules Rouff \& Cie Éd., 1885, p. 33-34. Louis Andrieux (1840-1931), «Avocat, journaliste et homme politique, préfet de police. Député du Rhône (1876-1885) puis des Basses-Alpes (1885-1889 et 1910-1924), préfet de Police (1879-1881). - Propriétaire de La petite République française. - Docteur ès lettres (Paris, 1927) » (source : notice, BNF http://catalogue.bnf.fr/ark:/12148/cb120557834)

66. Andrieux L., À travers la République, Paris, Payot, 1926, p.180. 
style parfois relâché et un langage un peu abscons, l'indicateur raconte comment il a pris des tracts «tandant à fauser les élections 68 ». Il souhaite travailler dans la construction de vélos, mais son patron est suspicieux sur ses allées et venues. Issu d'un milieu populaire, il n'apporte aucune indication sur le fonctionnement de la Ligue et ne peut qu'attester d'une distribution par des femmes de tracts. On demeure ainsi sans réponse sur les auxiliaires de la police qui ont alimenté les copieux rapports conservés aux Archives nationales et à la Préfecture de police de Paris.

On dispose en revanche des pseudonymes des auteurs de rapports. À la Préfecture de police de Paris, un agent est particulièrement au fait de l'activité des femmes entre 1902 et 1906 : Malaga. S'il souligne les liens des dames de l'Action libérale populaire - Ligue patriotique des Françaises avec le clergé ou la réaction, il évite un ton trop alarmiste ${ }^{69}$. Il indique ainsi, au soir d'une réunion qui rassemble 1400 personnes à Paris, qu'elle «n'a présenté qu'un intérêt politique très modéré. Elle a simplement prouvé que cette ligue a fait numériquement de grands progrès et devient une association de femmes importante 70 ». Il est présent dans les réunions publiques mais nous ne trouvons pas trace d'observation dans des réunions privées. Ses observations sont rarement erronées, souvent centrées sur l'action politique des ligues féminines.

Son collègue Fischer dresse des rapports plus incisifs. "Cladys », peutêtre une indicatrice, signe ses premiers rapports en 1904. Elle semble suivre de manière plus précise les réunions féminines. Enfin, on trouve quelques rapports de "Jean-Jacques », informateur d'une fiabilité inégale qui relate la fusion de la Ligue patriotique des Françaises et de la Ligue des femmes françaises en 1904, alors qu'elle ne sera effective qu'en 1933 71. À partir de 1906, Chatenet rédige la plupart des rapports conservés, prenant un soin attentif à la question des élections.

67. APPP, BA 902, "Comité des Dames ALP-LPDF », enveloppe envoyée de Paris, rue Etienne Dolet, 16h45, 5 mai 1906. ms: " Monsieur Lépine, Préfet, 7 B du Palais de Justice », E.V.

68. APPP, BA 902, "Comité des Dames ALP-LPDF », lettre de Bernardin Paul à Lépine Préfet de Paris, Passage d'Eupatoria, 20e, 5 mai 1906. Ms « Quand je t'ai prévenu il n'y a je ne sais combien de temps et que j'ai pu prendre connaissance du livre bleu de Bourges à l'abri $S^{t}$ Joseph rue de la Barre Je me suis pas trompé en filant c'était bien du cadre de femmes y a a pas d'erreur possibles et voici deux beaux facimil tandant à fauser les élections C'était distribué en abondance au proche de la Basilique de Montmartre ce matin à 8 a dix heures y a pas a nier voici des femmes " (sic).

69. APPP, BA 902, Malaga, 29 août 1902, dact. Le rapport porte sur une réunion des dames, il souligne que la présidente de l'association, la Baronne Reille, prend soin d'éviter toute contremanifestation « d'églantinards».

70. APPP, BA 902, Malaga, 3 mai 1903, dact.p.2.

71. APPP, BA 2013, Ligue patriotique des Françaises, Jean-Jacques, 2e Brigade, 1er Bureau du Cabinet, Extrait d'un rapport, dossier n 1885024 Ligue patriotique des Françaises, Paris, le 11 mars 1904.

72. Laurent S.-Y., Politiques de l'ombre..., op. cit., p. 258.

73. AN F7 13215, lettre manuscrite, sd, sn Hôtel du Casino, Ostende, ff.1, vers 1912-1913.

74. AN F7 13215, «Valette », 13 mai 1914. 
À la Sûreté générale, «Londres » et « Metz » signent bon nombre de rapports sur les comités de la Ligue patriotique des Françaises. En Province, les préfets centralisent l'information des commissaires de la Police spéciale relative aux Ligues d'une manière inégale, traduisant peut-être le degré d'empressement des représentants de l'État à s'acquitter de cette surveillance féminine. Selon Sébastien Laurent, qui reprend pour les désigner l'expression «d'administrateur politique ", ce rôle des préfets opère un continuum avec la police impériale ${ }^{72}$. Toutefois, au tournant du siècle, le corps préfectoral et les agents ne sont majoritairement pas issus des générations recrutées et formées sous le Second Empire. Les Commissaires spéciaux sont les auteurs de la majorité des rapports concernant la Ligue patriotique des Françaises, la Ligue des femmes françaises et les Dames royalistes. Contrairement aux militaires, ils semblent peu sympathiques à la cause des Ligueuses et attachés à la défense du régime républicain.

On peut faire l'hypothèse que les policiers sont parfois renseignés par les membres du clergé eux-mêmes. Dans un contexte de tensions très fortes entre les tenants d'un catholicisme libéral - accusés de modernisme - et les tenants d'une ligne intransigeante incarnée par le pape Pie X (1903-1914), il n'est pas impossible que certains membres du clergé en délicatesse avec l'institution aient transmis des informations. L'accusation d'activité électorale était un élément à charge pour les catholiques en disgrâce. On trouve ainsi dans le dossier F7 13215 une lettre anonyme, non datée, qui relate précisément les tensions internes à la compagnie de Jésus et dénonce la ligue comme cléricale et d'une loyauté exclusive au pape ${ }^{73}$. Le dossier "Courrier déchiré » conservé aux Archives nationales (F7 13 215) rassemble les documents trouvés dans la poubelle du secrétariat central de l'association, rue du Faubourg Saint-Honoré. L'une des informatrices pouvait être une femme de ménage, peut-être domestique de la famille Potron, propriétaire de l'immeuble où se situe le siège de la Ligue patriotique des Françaises et dont Cécile Potron est la trésorière.

\section{Se dérober au regard de l'État}

C'est en creux que l'on peut lire la méfiance des femmes catholiques à l'égard d'un régime pensé comme impie et de ses représentants considérés comme des agents de la persécution religieuse. La fiche de $\mathrm{M}^{\mathrm{lle}} \mathrm{de}$ Valette, activiste et conférencière, témoigne de la réticence des religieuses à faire connaître l'identité des pensionnaires «à cette adresse, on ne donne aucun renseignement $74 »$. On voit ainsi les femmes se dérober au regard jugé inquisiteur des agents de l'État. Au congrès de 1904, les orateurs se succèdent et fustigent le gouvernement Combes qui s'apprête à séparer l'État des Églises. Le bulletin de l'association rapporte les propos tenus par le Président de l'ACJF, avocat à la cour, Henry Bazire, devant 1500 ligueuses réunies à l'initiative des comités des $8^{\mathrm{e}}$ et $16^{\mathrm{e}}$ arrondissements de Paris : 
«Dans le tableau que l'orateur fait de la situation actuelle nous avons noté le passage suivant, où il flétrit l'indigne espionnage que subissent partout les femmes de fonctionnaires. À Paris, dans la foule anonyme, ces tracasseries sont moins sensibles ; mais regardez en province ?... Il n'est pas un département, pas de petite ville, pas de commune rurale où en ce moment l'espionnage, la délation hypocrite et méchante ne s'efforce de courber les têtes. Si la femme de l'agent-voyer va à la messe de six heures le dimanche; si l'instituteur a été vu causant avec M. Le Curé ; si le percepteur dont la fille est malade va chercher un remède chez les bonnes sœurs; immédiatement ces pauvres gens sont signalés par le tyranneau local à la loge voisine, puis à la sous-préfecture et c'est à la défaveur, l'arrêt dans le carrière ; bien heureux quand elle n'est pas brisée ${ }^{75}$ ».

Les agents-voyers, chargés de veiller à l'entretien et à l'aménagement des voies de communication et de la voirie municipale, sont présentés comme les espions du gouvernement, à la solde de la Maçonnerie. Ce sont les agents de la Sûreté qui sont visés ici, ceux de la Préfecture de police de Paris semblant moins inquisiteurs envers les catholiques et les mouvements conservateurs : n'avait-on pas vu l'ancien préfet de police Andrieux prendre part à la manifestation des mères de famille en juillet 1902 ? C'est vers le commissaire de police que la Baronne René Reille, qui prend la tête du comité de dames, envisage dans un premier temps de se tourner quand paraît l'annonce de la réunion du 9 août 1902 des femmes catholiques dans une feuille républicaine... Mais elle préfère finalement confier le service d'ordre aux hommes de l'entourage ${ }^{76}$. Une anecdote témoigne du peu d'efficacité prêté à la police municipale par la jeune Baronne Amédée Reille, conférencière et belle-fille de la Baronne Reille, qui sollicite la directrice d'école où elle tint une conférence pour la raccompagner à la station de métro : «elle redoutait la rencontre d'apaches et son mari lui avait également fait cette recommandation 77 ». Pour autant, ce sont bien des gardiens de la paix qui assurent la surveillance de certaines réunions publiques, telle celle du 21 juin 1903, salle Humbert de Romans où se pressent 3000 personnes pour écouter les ténors de la droite catholique libérale (Piou, Sangnier, François Coppée, de Castelnau etc.) et Mmes Reille, Piou et Villeneuve de la LPDF 78.

75. Henry Bazire, Conférence donnée à la Salle de la rue Pierre Charron, Paris, le 7 février 1904, publiée dans l'Écho de la LPDF, mars 1904, p.324.

76. APPP, BA 902, comité de Dames ALP, Rapport de Malaga, 9 août 1902, dact. « On parlait de signaler cette note au Commissaire de Police en lui demandant protection. En tout cas, on contrôlera très sévèrement les entrées et on évitera que parmi toutes ces femmes ne se glissent quelques filles tapageuses. Des hommes vont être invités à venir renforcer ce service de contrôle dans la crainte de désordre. Au comité des Dames comme à la cure de Plaisance, on paraît assez désappointé. On avait en effet manœuvré très discrètement en cas d'émeute : on comptait donc que les invités viendraient là comme à un sermon du soir et l'on craint fort maintenant que l'annonce de bagarre ne fasse peur aux invitées et ne les empêche de venir. » (ff.1-2). 
La suspicion à l'égard de l'État, incarné par la police spéciale, avait guidé le choix habile de la part de la hiérarchie catholique de solliciter une société religieuse à consécration secrète, les Filles du Cœur de Marie, fondée durant la Révolution Française pour échapper à la surveillance du nouveau gouvernement. Comme nous l'avons montré par ailleurs, la discrétion et l'obéissance des Filles de Marie permettaient de s'assurer du contrôle par des clercs de l'association féminine, sans pour autant qu'ils n'apparaissent officiellement dans les statuts. Le Cardinal Montagnini, dans une lettre au Secrétaire d'État du Vatican, insiste sur l'aide des religieuses à la Ligue :

«Un certain nombre de filles de Marie s'occupent très activement de la Ligue patriotique des Françaises unie à l'Action libérale populaire. Elles en organisent les cadres principaux des organisations à travers la France. C'est grâce à leur concours qu'on a pu regrouper plus de trois cent mille adhérentes bien organisées et disciplinées car personne dans les Comités ne sait qu'elles sont filles de Marie, aussi peuvent-elles maintenir la même discipline dans tous les comités 79 ».

La discipline et l'obéissance sont tout aussi précieuses que le vœu du secret, qui permet aux membres de la Société d'échapper au regard des laïcs et de l'administration. Toutefois, la proximité avec la compagnie de Jésus, qui a pour particularité de ne pas dépendre des évêques mais d'être placée directement sous l'autorité du Pape, échappant de facto avant 1905 à la surveillance ministérielle, est bien notée par les agents. En 1906, la LPDF envisage de créer des dispensaires avec les sommes recueillies pour l'œuvre de la Presse, en vue de prodiguer des soins aux adhérentes et d'y faire de la propagande. « Pour ne pas éveiller l'attention, ces dispensaires porteraient le nom, non de la Ligue mais du médecin qui y donnerait des soins. Chacun d'eux serait administré par des dames faisant partie de la Ligue et recevrait une subvention 80 ». Ces religieuses qui se dérobent au regard des agents de l'État sont, en revanche, dans le collimateur de différents dicastères de la Curie romaine, de l'Épiscopat et de la Compagnie de Jésus.

$* * *$

77. APPP, BA 902, Comité de Dames ALP-LPDF, Rapport de Michaut, Paris, le 16 mars 1903, dact. bleu, p.2.

78. APPP, BA 902, Comité de Dames ALP-LPDF, Rapport de M. Leproust, Commissaire de police, 1re Brigade, DG des Recherches, Cabinet 1er Bureau, Paris, le 21 juin 1903.

79. ASV, Seg.di Stato, Anno 1907, rubr.248, facs.2, n¹791. Cette lettre est anonyme et non datée, elle s'insère dans un dossier qui fournit des renseignements fournis par Piou au Card. Montagnini au sujet des liens entre les Filles de Marie, l’Action libérale populaire et la Ligue patriotique des Françaises.

80. APPP, BA 902, Fischer, note, Paris, le 23 février 1906, dact. 
Les ligues féminines offrent un point de vue pour saisir les effets du changement du régime des cultes sur les dispositifs de surveillance. Du point de vue de l'État, c'est tout autant l'intervention jugée intempestive de femmes dans le champ politique que le fait qu'elles soient catholiques qui appelle une surveillance spécifique jusqu'en 1914. Les femmes catholiques, qui manifestent un attachement à l'Église et une fidélité absolue au Saint-Siège dans un contexte de fortes tensions diplomatiques, sont soupçonnées d'allégeance à une puissance étrangère. Rassemblées en comités électoraux et en ligue, elles représentent une menace pour la civilisation électorale : par leurs interventions financières, médiatiques, techniques dans les campagnes électorales mais aussi par leur influence sur les enfants, les femmes obèrent le libre exercice du droit de suffrage. Le rôle attribué à l'influence féminine par les clercs, les hommes conservateurs et les agents de la Sûreté ou de la Préfecture de police, témoigne d'une représentation partagée de la division des sexes et du genre. Une catégorie de militantes, les Filles de Marie, ces religieuses consacrées dans le secret, échappe aux regards préfectoraux pendant un temps. Mais elle est bien présente chez les informateurs du Vatican qui veillent, de l'autre côté des Alpes, à ce que les militantes de la Ligue patriotique des Françaises ne s'engagent pas dans une voie trop libérale et politique. L'intervention des ligueuses fait aussi l'objet d'un regard attentif au sein de l'Église : membres de la Compagnie de Jésus, Supérieure des Filles de Marie, Évêques s'attachent à garantir l'orthodoxie et l'orthopraxie des fidèles. La surveillance ecclésiale est d'abord guidée par des impératifs propres à l'institution religieuse, qui ne rentrent pas nécessairement en congruence avec le souci de l'ordre public et de la stabilité du régime. La période de crise qui s'ouvre en 1880 et s'achève avec la Grande guerre entraîne une reconsidération du péril clérical. La reprise des relations diplomatiques entre la République et le Vatican en mai 1921, les évolutions sociales et politiques reconfigurent le péril clérical. Les catholiques de la Ligue féminine d'action catholique deviennent un facteur d'ordre social et de stabilité politique. Se tenant en retrait des joutes électorales, elles investissent l'action sociale et la formation civique des femmes. Les militantes d'action catholique sortent du viseur et feront place, à droite, aux militantes des ligues de l'entre-deux-guerres. 